\title{
Occurrence and molecular epidemiology of Giardia duodenalis infection in dog populations in eastern Spain
}

Manuel Adell-Aledón ${ }^{1}$, Pamela C. Köster², Aida de Lucio², Paula Puente², Marta Hernández-de-Mingo², Paula Sánchez-Thevenet ${ }^{1}$, María Auxiliadora Dea-Ayuela ${ }^{3}$ and David Carmena ${ }^{1,2^{*}}$

\begin{abstract}
Background: Giardia duodenalis is one of the most common enteric parasites in domestic animals including dogs. Young animals are more prone to the infection, with clinical manifestations ranging from asymptomatic to acute or chronic diarrhoea. Dogs are primarily infected by canine-specific (C-D) assemblages of G. duodenalis. However, zoonotic assemblages $A$ and $B$ have been increasingly documented in canine isolates, raising the question of whether and to which extent dogs can act as natural reservoirs of human giardiosis.

Methods: In this cross-sectional epidemiological survey we assessed the molecular diversity of G. duodenalis in dogs in the province of Castellón, Eastern Spain. A total of 348 individual faecal samples from sheltered $(n=218)$, breeding $(n=24)$, hunting $(n=68)$, shepherd $(n=24)$, and pet $(n=14)$ dogs were collected between 2014 and 2016. Detection of $G$. duodenalis cysts in faecal material was carried out by direct fluorescence microscopy as a screening test, whereas a qPCR targeting the small subunit ribosomal RNA gene of the parasite was subsequently used as a confirmatory method.
\end{abstract}

Results: Giardia duodenalis was detected in 36.5\% (95\% Cl: 31.6-41.7\%) of dogs. No significant differences in prevalence rates could be demonstrated among dogs according to their sex and geographical origin, but breeding (45.8\%; 95\% Cl: 27.9-64.9\%) and sheltered (40.4\%; 95\% Cl: 34.1-47.0\%) dogs harboured significantly higher proportions of $\mathrm{G}$. duodenalis. Multi-locus sequence-based genotyping of the glutamate dehydrogenase and $\beta$-giardin genes of $\mathrm{G}$. duodenalis allowed the characterization of 35 canine isolates that were unambiguously assigned to assemblages A (14. $3 \%), B(22.9 \%), C(5.7 \%)$, and D (37.1\%). A number of inter-assemblage mixed infections including A + B (11.4\%), A + D (2.9\%), and A + B + D (5.7\%) were also identified.

Conclusions: Data presented here are strongly indicative of high infection pressures in kennelled animals. Zoonotic sub-assemblages All, BIII, and BIV were responsible for a considerable proportion of the G. duodenalis infections detected, but very few of the genotypes identified have been previously documented in Spanish human populations. Although possible, zoonotic transmission between dogs and humans seems an infrequent event in this Spanish region.

Keywords: Giardia duodenalis, Protozoa, Dogs, Molecular epidemiology, Castellón, Spain

\footnotetext{
* Correspondence: dacarmena@isciii.es

${ }^{1}$ CEU Cardenal Herrera University, C/ Grecia, 31, 12006 Castellón de la Plana, Castellón, Spain

${ }^{2}$ Parasitology Reference and Research Laboratory, National Centre for

Microbiology, Health Institute Carlos III, Ctra. Majadahonda-Pozuelo Km 2,

28220 Majadahonda, Madrid, Spain

Full list of author information is available at the end of the article
} International License (http://creativecommons.org/licenses/by/4.0/), which permits unrestricted use, distribution, and reproduction in any medium, provided you give appropriate credit to the original author(s) and the source, provide a link to the Creative Commons license, and indicate if changes were made. The Creative Commons Public Domain Dedication waiver (http://creativecommons.org/publicdomain/zero/1.0/) applies to the data made available in this article, unless otherwise stated. 


\section{Background}

Pet animals in general and dogs in particular are increasingly regarded as true family members in many homes globally. In the UK in 2016 canine population stood at around 8.5 million, with $24 \%$ households owning a dog [1]. Since the early 1980s, the human-canine bonding has been demonstrated to significantly improve the health and well-being of both people and dogs by strengthening emotional, psychological, and physical interactions [2]. Indeed, dogs are nowadays successfully used in hospital-based animal assisted therapy programs [3]. However, dogs can act as natural reservoirs of a number of zoonotic parasitic infections including leishmaniosis, giardiosis, cryptosporidiosis, echinococcosis, dirofilariosis, and toxocariosis, particularly if improperly cared for or mistreated $[4,5]$.

The enteric protozoan parasite Giardia duodenalis is one of the most commonly detected pathogens associated with diarrhoea in humans and animals, including domestic dogs $[6,7]$. As in other host species, canine infections by $G$. duodenalis can present with a broad range of clinical manifestations from asymptomatic to acute or chronic disease [8,9]. Giardia duodenalis is currently regarded as a complex of eight $(\mathrm{A}-\mathrm{H})$ genotypes, also known as assemblages, displaying distinct host specificities and transmission patterns. Assemblages A and B have the widest host ranges, infecting humans, domestic animals and livestock and a large number of wildlife species, and are therefore considered zoonotic. On the contrary, assemblages $\mathrm{C}-\mathrm{H}$ appear to infect a far more limited number of host species. Thus, assemblages $\mathrm{C}$ and $\mathrm{D}$ are found mainly in dogs, assemblage $\mathrm{E}$ in hoofed animals, assemblage $F$ in cats, assemblage $G$ in rodents, and assemblage $\mathrm{H}$ in marine mammals $[10,11]$.

The potential role of domestic dogs as a source of human giardiosis has been a topic of intense debate and research in the last years, with still uncertain conclusions [6]. Whereas large household- or community based surveys conducted in Cambodia [12], Peru [13], and Spain [14] concluded that dogs play a minor or no role at all in the transmission of $G$. duodenalis infections to humans, other studies suggested that transmission would be possible under favourable epidemiological conditions $[15,16]$.

In Spain, the presence of G. duodenalis in canine populations has been investigated in a limited number of epidemiological surveys using coprological examination by either conventional or direct immunofluorescence microscopy, post-mortem examination, or PCR-based methods [7, 17]. Giardiosis has been documented at infection rates of $6-38 \%$ in sheltered and hunting dogs in Barcelona $[18,19]$, of $1-33 \%$ in sheltered dogs in Córdoba and Álava [20, 21], and of $7-16 \%$ in sheltered and stray dogs in Murcia and Madrid [22-24]. Giardia duodenalis cysts have also been identified in soil samples from public parks in Madrid [25], but not in Córdoba [20]. Regarding the potential zoonotic transmission of the parasite, dog ownership has been linked with an increase in the prevalence odds of human giardiosis in Álava [26], although no dog-human transmission could be demonstrated in a recent household-based survey in the same geographical area [14]. Genotyping data are even scarcer, being only reported in few molecular studies carried out in Madrid [24], Catalonia [19], and the Basque Country [14, 21].

In this molecular epidemiological survey we present novel data on the presence, molecular diversity and frequency of $G$. duodenalis in different $\operatorname{dog}$ populations in Castellón, a geographical region where the occurrence of this protozoan parasite had not been previously studied. Molecular data on the G. duodenalis assemblages and subassemblages found was used to evaluate the potential role of domestic dogs as suitable reservoirs of human giardiosis.

\section{Methods \\ Study area}

Castellón, one of the three provinces forming the Autonomous Region of Valencia in Eastern Spain, extends over $6632 \mathrm{~km}^{2}$ and has a total population of 582,327 inhabitants, a third of them living in the capital city Castellón de la Plana [27]. The province is divided in 135 municipalities distributed in eight administrative regions (Fig. 1). There are officially 151,311 domestic dogs in Castellón [28]. Of them, a total of 21,936 dogs belong to hound-type breeds commonly used in hunting, whereas an undetermined number of guard or shepherd dogs are used in agricultural exploitations in rural areas [28]. Out of the five (all privately owned) animal shelters operating in Castellón, four agreed to participate in this survey. One of them was subcontracted by the town hall, managing most stray, abandoned, or surrendered animals in the province. Besides providing attention and care, this centre was also a licensed breeding kennel and developed adoption programs to find new homes for the collected dogs. Owners of hunting, shepherd, and pet dogs were personally contacted and requested to voluntary participate in the present survey.

\section{Faecal sample collection}

A total of 348 faecal dropping samples from individual dogs were collected during the period July 2014 and July 2016. Faecal specimens belonging to dogs from animal shelters $(n=218)$ or breeding dogs which were for sale ( $n=24)$ were collected at the time of daily box cleaning. Faecal samples from hunting $(n=68)$, shepherd $(n=24)$, and pet $(n=14)$ dogs were collected just or soon after defecation. In all cases faecal samples were obtained within $24 \mathrm{~h}$ of excretion. Obtained faecal specimens were placed in screw-topped specimen containers and 


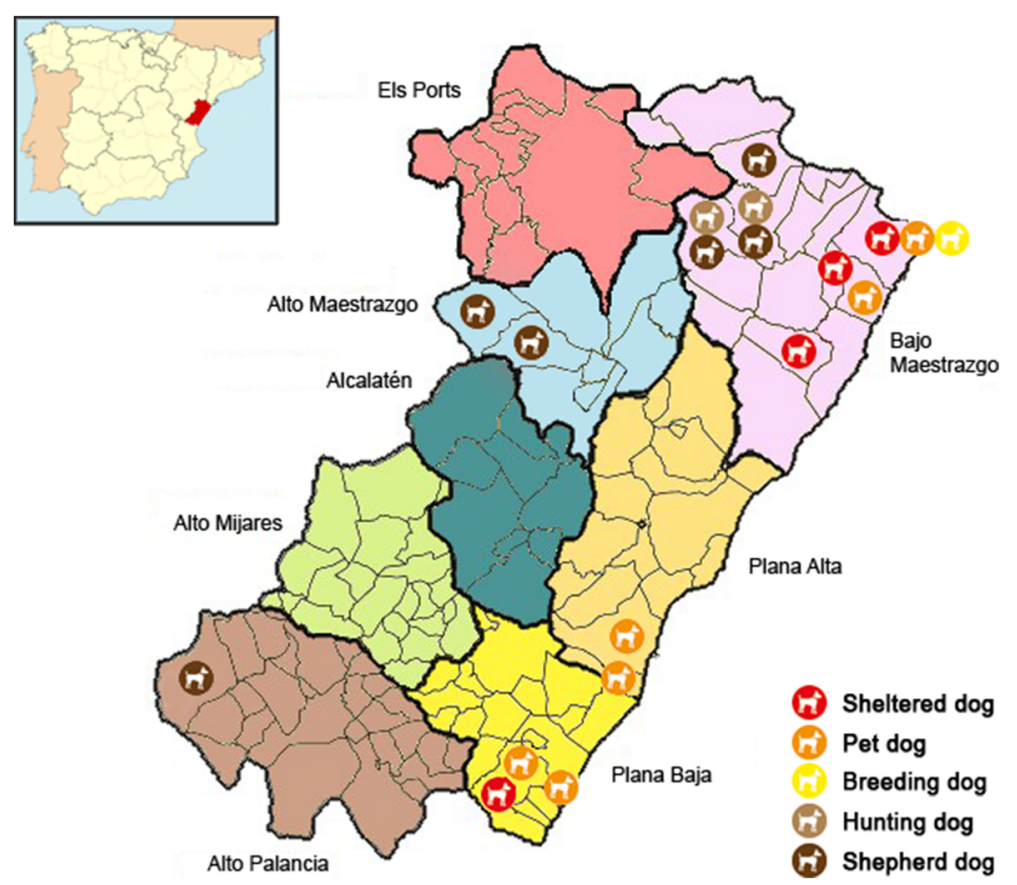

Fig. 1 Map of the administrative divisions of the province of Castellón. The municipalities where sampling was conducted and the status of the dog sub-populations are indicated. The location of Castellón in Spain is highlighted in red in the upper left corner. Images used are in the public domain and have been downloaded from https://eswikipediaorg/wiki/Anexo:Municipios_de_la_provincia_de_Castell\%C3\%B3n

uniquely labelled indicating identification number and date of collection. Information regarding sex, status, and geographical origin of the animal was also recorded. Age data was only available for a limited number of animals and therefore this variable was not included in our analyses. Faecal specimens were transported in refrigerated boxes to the laboratory at the CEU Cardenal Herrera University (Castellón), stored at $4{ }^{\circ} \mathrm{C}$, and processed within $24 \mathrm{~h}$ of collection. Two aliquots of each faecal sample were prepared as follows: i) one was resuspended in $5-10 \mathrm{~mL}$ of $10 \%$ formal saline solution and kept until examination by fluorescence microscopy; ii) the other was preserved in $70 \%$ ethanol and shipped to the Parasitology Reference and Research Laboratory, Spanish National Centre for Microbiology (Majadahonda) for further molecular analyses.

\section{Direct fluorescent antibody test}

A direct fluorescent antibody test (DFAT) was used to detect Giardia cysts by fluorescence microscopy. Briefly, faecal material was processed using the formalin-ethyl acetate sedimentation concentration method as described elsewhere [22]. Ten $\mu \mathrm{L}$ of concentrated faecal material were placed on welled slides. Smears were airdried, methanol fixed, stained with fluorescein-labelled mouse monoclonal antibodies (Merifluor ${ }^{\circ}$ Cryptosporidium/Giardia, Meridian Bioscience, OH, USA), and examined at $400 \times$ magnification.

\section{DNA extraction and purification}

Total DNA was extracted from those faecal samples that tested positive by DFAT. An aliquot ( $200 \mathrm{mg}$ ) of each faecal sample in $70 \%$ ethanol was processed using the QIAamp ${ }^{\circ}$ DNA Stool Mini Kit (QIAGEN, Hilden, Germany) according to the manufacturer's instructions. Purified DNA samples $(200 \mu \mathrm{L})$ were stored at $-20{ }^{\circ} \mathrm{C}$ for further downstream molecular analysis. A water extraction control was routinely included in each sample batch processed.

\section{Molecular detection of Giardia duodenalis}

Detection of G. duodenalis DNA was achieved using a real-time PCR (qPCR) method targeting a 62-bp region of the small subunit ribosomal RNA (ssu rRNA) gene of the parasite [29]. Amplification reactions were conducted in a volume of $25 \mu \mathrm{L}$ containing $3 \mu \mathrm{L}$ of template DNA, 12.5 pmol of primers Gd-80F and Gd-127R, 10 pmol of probe (Additional file 1: Table S1), and $12.5 \mu \mathrm{L}$ TaqMan ${ }^{\circ}$ Gene Expression Master Mix (Applied Biosystems, CA, USA). Detection of parasitic DNA was performed on a Corbett Rotor-Gene 6000 real-time PCR cycler (Qiagen Corbett, Hilden, Germany) using an amplification protocol consisting of an initial hold step of 2 min at $55^{\circ} \mathrm{C}$ and $15 \mathrm{~min}$ at $95^{\circ} \mathrm{C}$ followed by 45 cycles of $15 \mathrm{~s}$ at $95{ }^{\circ} \mathrm{C}$ and $1 \mathrm{~min}$ at $60{ }^{\circ} \mathrm{C}$. The ramping of the machine was $10{ }^{\circ} \mathrm{C} / \mathrm{s}$ in every step. No-template water (negative) and DNA (positive) controls of genomic DNA were included in each PCR run. 
Molecular characterization of Giardia duodenalis isolates Giardia duodenalis isolates that tested positive by realtime PCR were subsequently assessed at the glutamate dehydrogenase $(g d h)$ and $B$-giardin $(b g)$ loci. A seminested-PCR protocol was used to amplify a $\sim 432$-bp fragment of the $g d h$ gene [30]. PCR reaction mixtures $(25 \mu \mathrm{L})$ consisted of $5 \mu \mathrm{L}$ of template DNA, $0.5 \mu \mathrm{M}$ of each primer $(\mathrm{GDHeF} / \mathrm{GDHiR}$ in the primary reaction and GDHiF/GDHiR in the secondary reaction, respectively, Additional file 1: Table S1), 2.5 units of MyTAQ ${ }^{\mathrm{m}}$ DNA polymerase (Bioline $\mathrm{GmbH}$, Luckenwalde, Germany), and $5 \mu \mathrm{L}$ of MyTAQ ${ }^{\mathrm{ma}}$ Reaction Buffer containing $5 \mathrm{mM}$ dNTPs and $15 \mathrm{mM} \mathrm{MgCl}$. Both amplification protocols consisted of an initial denaturation step at $95{ }^{\circ} \mathrm{C}$ for $3 \mathrm{~min}$, followed by 35 cycles of $95{ }^{\circ} \mathrm{C}$ for $30 \mathrm{~s}, 55^{\circ} \mathrm{C}$ for $30 \mathrm{~s}$ and $72{ }^{\circ} \mathrm{C}$ for $1 \mathrm{~min}$, with a final extension of $72{ }^{\circ} \mathrm{C}$.

Similarly, a $\sim 511$-bp fragment of the $b g$ gene of $G$. duodenalis was amplified using a nested-PCR protocol [31]. PCR reaction mixtures $(25 \mu \mathrm{L})$ consisted of $3 \mu \mathrm{L}$ of template DNA, 0.4 $\mu \mathrm{M}$ of each primer (G7_F/ G759_R in the primary reaction and G99_F/ G609_R in the secondary reaction, respectively, Additional file 1: Table S1), 2.5 units of MyTAQ $^{\mathrm{m}}$ DNA polymerase (Bioline $\mathrm{GmbH}$ ), and $5 \mu \mathrm{L}$ of $\mathrm{MyTAQ}^{\mathrm{m}}$ Reaction Buffer containing $5 \mathrm{mM}$ dNTPs and $15 \mathrm{mM} \mathrm{MgCl}$. The primary PCR reaction was carried out with the following amplification conditions: 1 cycle of $95{ }^{\circ} \mathrm{C}$ for 7 min, followed by 35 cycles of $95{ }^{\circ} \mathrm{C}$ for $30 \mathrm{~s}, 65{ }^{\circ} \mathrm{C}$ for $30 \mathrm{~s}$, and $72{ }^{\circ} \mathrm{C}$ for $1 \mathrm{~min}$ with a final extension of $72{ }^{\circ} \mathrm{C}$ for $7 \mathrm{~min}$. The conditions for the secondary PCR were identical to the primary PCR except that the annealing temperature was $55^{\circ} \mathrm{C}$.

PCR reactions were carried out on a 2720 thermal cycler (Applied Biosystems). Laboratory-confirmed positive and negative DNA samples were routinely used as controls and included in each round of PCR. PCR amplicons were visualized on 2\% D5 agarose gels (Conda, Madrid, Spain) stained with Pronasafe nucleic acid staining solution (Conda). Positive-PCR products were directly sequenced in both directions using the internal primer set described above. DNA sequencing was conducted by capillary electrophoresis using the BigDye ${ }^{\circ}$ Terminator chemistry (Applied Biosystems).

\section{Data analyses}

The chi-square test was used to compare parasite prevalence rates in the canine population under study by sex, status (sheltered, breeding, pet, hunting or shepherd) and geographical origin of the dogs. A probability $(P)$ value $<0.05$ was considered evidence of statistical significance. Data were analysed with the free software RStudio Version 1.0.44 (https://www.rstudio.com/) using the Epitools library.
Raw sequencing data in both forward and reverse directions were viewed using the Chromas Lite version 2.1 sequence analysis program (https://technelysium.com.au/wp/chromas/). The BLAST tool (http://blast.ncbi.nlm.nih.gov/Blast.cgi) was used to compare nucleotide sequences with sequences retrieved from the National Center for Biotechnology Information (NCBI) database. Generated DNA consensus sequences were aligned to appropriate reference sequences using the MEGA 6 free software (http://www.megasoftware.net/) to identify Giardia species and assemblages/sub-assemblages [32].

For the identification of the phylogenetic inferences among the identified positive samples, a phylogenetic tree was inferred using the Neighbor-Joining method in MEGA 6. The evolutionary distances were computed using the Kimura 2-parameter method, and modelled with a gamma distribution. The reliability of the phylogenetic analyses at each branch node was estimated by the bootstrap method using 1000 replications. Representative reference sequences of the different $G$. duodenalis sub-assemblages taken from the NCBI database were also included in the phylogenetic analysis for comparative purposes.

The sequences obtained in this study have been deposited in GenBank under accession numbers MF285561 to MF285603.

\section{Results}

\section{Detection of $G$. duodenalis in canine faecal samples}

The overall prevalence of $G$. duodenalis in the investigated dog population was estimated at 36.5\% [95\% Confident Interval (CI): 31.6-41.7\%]. Out of the 127 dogs that tested positive by DFAT, $81.1 \%(103 / 127)$ were confirmed by qPCR, whereas 18.9 (24/127) failed to be detected by the latter method. The qPCR-positive samples had cycle threshold (Ct) values ranging from 21.4 to 39.6 (mean: 29.4; SD: 3.8). Overall, 68.9\% (71/103) of the Giardia-positive isolates by qPCR had Ct values $\geq 30$ (Additional file 2 : Figure S2). Regarding consistency, all the faecal samples processed and analysed were hard and formed or soft but formed. No loose or liquid faecal samples were noticed in the studied canine population.

Table 1 shows the occurrence of G. duodenalis according to the sex, status, and region of origin of the surveyed dogs. The male/female ratio was 1.3. Giardia duodenalis was more prevalent in female dogs than in male dogs, although this difference was not statistically significant $(P=0.513)$. Regarding dog status, detected $G$. duodenalis prevalences ranged from $20.6 \%$ (95\% CI, 12.7-31.6\%) in hunting dogs to $45.8 \%$ (95\% CI: $27.9-64.9 \%$ ) in breeding dogs. Statistically significant differences were found between hunting and breeding $\operatorname{dogs}(P=0.017)$ and between hunting and sheltered $\operatorname{dogs}(P=0.003)$. No obvious differences in the geographical distribution pattern of $G$. duodenalis was 
Table 1 Prevalence and 95\% confidence intervals (Cls) of Giardia duodenalis in dogs, as determined by direct fluorescent antibody assay. Results have been categorized according to sex, status, and geographical region of origin of the investigated dogs $(n=348)$ from Castellón, Spain, 2014-2016. Chi-square determined P-values are indicated

\begin{tabular}{|c|c|c|c|c|c|}
\hline Variable & No. & Giardia duodenalis & Percent & $95 \% \mathrm{Cl}$ & $P$-value \\
\hline \multicolumn{6}{|l|}{$\operatorname{Sex}^{a}$} \\
\hline Male & 158 & 46 & 29.1 & $22.6-36.6$ & \multirow[t]{2}{*}{.513} \\
\hline Female & 119 & 39 & 32.8 & $25.0-41.6$ & \\
\hline \multicolumn{6}{|l|}{ Status } \\
\hline Sheltered dog & 218 & 88 & 40.4 & $34.1-47.0$ & \multirow[t]{5}{*}{.045} \\
\hline Breeding dog & 24 & 11 & 45.8 & $27.9-64.9$ & \\
\hline Pet dog & 14 & 5 & 35.7 & $16.3-61.2$ & \\
\hline Hunting dog & 68 & 14 & 20.6 & $12.7-31.6$ & \\
\hline Shepherd dog & 24 & 9 & 37.5 & $21.2-57.3$ & \\
\hline \multicolumn{6}{|l|}{ Origin $^{b}$} \\
\hline Alcalatén & 5 & 4 & 80.0 & $37.6-96.4$ & \multirow[t]{6}{*}{$.152^{c}$} \\
\hline Alto Palancia & 10 & 4 & 40.0 & $16.8-68.7$ & \\
\hline Alto Maestrazgo & 12 & 2 & 16.7 & $4.7-44.8$ & \\
\hline Bajo Maestrazgo & 175 & 73 & 41.7 & $34.7-49.1$ & \\
\hline Plana Baja & 45 & 14 & 31.1 & $19.5-45.7$ & \\
\hline Plana Alta & 101 & 30 & 29.7 & $21.7-39.2$ & \\
\hline
\end{tabular}

${ }^{\mathrm{a}}$ No data available from 71 dogs

${ }^{b}$ Place of living of the dog at the moment of sampling. For sheltered dogs the term refers to the municipality where the animal was captured or surrendered ${ }^{\mathrm{c}}$ Dogs from the municipality of Alcalatén were not included in the statistical analysis because of low sample size

demonstrated $(P=0.152)$, although the infection was more frequently detected in Alcalatén (80.0\%; 95\% CI: 37.696.4\%) and Bajo Maestrazgo (41.7\%; 95\% CI: 34.7-49.1\%), with Alto Maestrazgo (16.7\%; 95\% CI: 4.7-44.8\%) and Plana Alta (29.7\%; 95\% CI: 21.7-39.2\%) harbouring the lowest infection rates.

\section{Molecular characterization of $G$. duodenalis isolates}

Out of the 103 G. duodenalis isolates confirmed by qPCR, $34.0 \%(35 / 103)$ were successfully amplified at the $g d h$ and/ or $b g$ markers. Multi-locus genotyping data were produced for $28.6 \%(10 / 35)$ of them, whereas $51.4 \%(18 / 35)$ and $20.0 \%(7 / 35)$ of the canine isolates were only amplified at the $g d h$ or the $b g$ loci, respectively. Sequence analyses revealed the presence of assemblages A (14.3\%; 5/ $35)$, B $(22.9 \%$; $8 / 35), C(5.7 \% ; 2 / 35)$, and D $(37.1 \%, 13 / 35)$ (Tables 2 and 3). A number of mixed infections with more than one assemblage of $G$. duodenalis interpreted as $\mathrm{A}+\mathrm{B}$ (11.4\%; 4/35), A + D (2.9\%; 1/35), and A + B + D (5.7\%; $2 /$ 35) were also identified (Table 4). Sheltered dogs harboured the widest range of $G$. duodenalis assemblages, including $\mathrm{A}, \mathrm{B}, \mathrm{C}$, and D. Breeding and hunting dogs were found infected by assemblages $\mathrm{A}, \mathrm{B}$, and $\mathrm{D}$, whereas $\mathrm{A}$ and $B$ were the only assemblages identified in shepherd dogs. None of the G. duodenalis isolates obtained from pet dogs could be characterized at the assemblage level. Interestingly, all seven inter-assemblage mixed infections were detected in kennelled animals, three of them in breeding dogs and the remaining four in sheltered dogs (Tables 2, 3 and 4).

Sub-genotyping data of the $21 \mathrm{gdh}$ sequences with only unequivocal, single-assemblage infections are summarized in Table 2. Two isolates were identified as AII, differing by one to two single-nucleotide polymorphisms (SNPs) with a 405-bp fragment stretching from positions 78-482 of reference sequence L40510. No isolates belonging to sub-assemblages AI or AIII were detected. However, BIII and BIV isolates exhibited a much greater genetic diversity at the nucleotide level. Sequence alignment analyses of BIII isolates with reference sequence AF069059 allowed the identification of a 402 to 412-bp stretch, equivalent to positions 44/54-455 of AF069059. All three BIII isolates differed by seven to 13 SNPs with AF069059, including a high proportion of heterozygous positions (double peaks) detected during chromatogram inspection. Similarly, the two canine isolates assigned to BIV differed by two to four SNPs with a 388/402-bp fragment of reference sequence L40508. Interestingly, one of them (MF285566) showed 100\% homology with the second most common BIV genotype (KT310363) detected in clinical patients in Spain [33]. Discordant genotype results BIII/BIV (very likely representing mixed intra-assemblage infections) were detected in four additional isolates (Table 4). The only $\mathrm{C}$ isolate genotyped at the $g d h$ gene was identical to a 413-bp fragment (positions 78-490) of reference sequence U60984. Finally, the 
Table 2 Diversity, frequency, and molecular features of canine-derived Giardia duodenalis isolates at the glutamate dehydrogenase locus. Castellón, Eastern Spain, 2014-2016. GenBank accession numbers are provided. Novel genotypes are shown underlined

\begin{tabular}{|c|c|c|c|c|c|c|c|}
\hline Assemblage & Sub-assemblage & No. isolates & Dog status & $\begin{array}{l}\text { Reference } \\
\text { sequence }\end{array}$ & $\begin{array}{l}\text { Stretch } \\
(\mathrm{pb})\end{array}$ & Single nucleotide polymorphism(s) & $\begin{array}{l}\text { GenBank } \\
\text { accession } \\
\text { number }\end{array}$ \\
\hline \multirow[t]{2}{*}{ A } & All & 1 & Hunting & L40510 & $78-482$ & A175R, A271R & MF285561 \\
\hline & & 1 & Sheltered & L40510 & $78-482$ & C198T & MF285562 \\
\hline \multirow[t]{5}{*}{ B } & BIII & 1 & Shepherd & AF069059 & $54-455$ & $\begin{array}{l}\text { C87T, G93R, T95Y, C99Y, T147Y, G150R, T230Y, } \\
\text { G277R, C309T }\end{array}$ & MF285563 \\
\hline & & 1 & Sheltered & AF069059 & $54-455$ & $\begin{array}{l}\text { C87T, T138Y, T147Y, T219Y, T237Y, C309Y, C330Y, } \\
\text { G354A, G372R, T382K, G406R, A414R, G444R }\end{array}$ & MF285564 \\
\hline & & 1 & Sheltered & AF069059 & $44-455$ & C87Y, C99Y, T147Y, G189R, C309T, G354R, G406R & MF285565 \\
\hline & BIV & 1 & Shepherd & $\llcorner 40508$ & $80-481$ & T183C, T387C, C396T, C423T & MF285566 \\
\hline & & 1 & Sheltered & L40508 & $\begin{array}{l}109- \\
496\end{array}$ & C133A, T464Y & MF285567 \\
\hline C & - & 1 & Sheltered & U60984 & $78-490$ & No & MF285568 \\
\hline \multirow[t]{9}{*}{ D } & - & 1 & Sheltered & U60986 & $80-481$ & No & MF285569 \\
\hline & - & 1 & Sheltered & U60986 & $80-481$ & G225R, T429C, G441A, & MF285570 \\
\hline & - & 2 & $\begin{array}{l}\text { Breeding, } \\
\text { Sheltered }\end{array}$ & U60986 & $80-481$ & $\mathrm{~T} 240 \mathrm{C}$ & MF285571 \\
\hline & - & 1 & Hunting & U60986 & $80-481$ & T240C, C375T & MF285572 \\
\hline & - & 1 & Sheltered & U60986 & $80-481$ & T240Y, T429Y, G441R & MF285573 \\
\hline & - & 3 & Sheltered & U60986 & $80-481$ & T240C, T429C, G441A, T459A & MF285574 \\
\hline & - & 1 & Sheltered & U60986 & $80-481$ & C375T & MF285575 \\
\hline & - & 2 & $\begin{array}{l}\text { Hunting, } \\
\text { Sheltered }\end{array}$ & U60986 & $80-481$ & T429C, G441A & MF285576 \\
\hline & - & 1 & Sheltered & U60986 & $80-481$ & C216Y, T429C, G441A, C471Y & MF285577 \\
\hline
\end{tabular}

$K: A / T ; R: A / G ; Y: C / T$

13 isolates assigned to the assemblage D of G. duodenalis were distributed in nine distinct, including a novel (MF285575), genotypes differing between none and four SNPs in a 402-bp fragment stretching from positions 80-481 of reference sequence U60986. The phylogenetic analysis revealed that our A-D sequences clustered together in well-supported clades with the corresponding assemblage and sub-assemblage reference sequences from NCBI, as they also did with sequences of human and canine origin previously documented in other Spanish studies [14, 21, 33] and included here for comparative purposes (Fig. 2).

Table 3 Diversity, frequency, and molecular features of canine-derived Giardia duodenalis isolates at the beta-giardin locus. Castellón, Eastern Spain, 2014-2016. GenBank accession numbers are provided. Novel genotypes are shown underlined

\begin{tabular}{|c|c|c|c|c|c|c|c|}
\hline Assemblage & Sub-assemblage & No. isolates & $\begin{array}{l}\text { Dog } \\
\text { status }\end{array}$ & $\begin{array}{l}\text { Reference } \\
\text { sequence }\end{array}$ & $\begin{array}{l}\text { Stretch } \\
(\mathrm{pb})\end{array}$ & Single nucleotide polymorphism(s) & $\begin{array}{l}\text { GenBank accession } \\
\text { number }\end{array}$ \\
\hline \multirow[t]{5}{*}{$\bar{A}$} & All & 1 & Hunting & AY072723 & $97-590$ & T187Y & MF285578 \\
\hline & & 1 & Hunting & AY072723 & $102-590$ & A227R, G434A & MF285579 \\
\hline & & 1 & Hunting & AY072723 & $98-590$ & G261A, G277A, T329A, T564C & MF285580 \\
\hline & & 1 & Sheltered & AY072723 & $106-587$ & T390Y & MF285581 \\
\hline & Alll & 1 & Shepherd & AY072724 & $103-590$ & A125R, C414Y, T558Y & MF285582 \\
\hline B & - & 1 & Breeding & AY072727 & $104-590$ & $\begin{array}{l}\text { G159A, C165T, C309T, C324T, C393T, } \\
\text { T471C }\end{array}$ & MF285583 \\
\hline C & - & 1 & Sheltered & AY545646 & $11-500$ & G37A, C451T & MF285584 \\
\hline \multirow[t]{3}{*}{$\mathrm{D}$} & - & 1 & Sheltered & AY545647 & $105-590$ & No & MF285585 \\
\hline & - & 1 & Sheltered & AY545647 & $105-590$ & G129A, A201G, C207A, A455R & MF285586 \\
\hline & - & 1 & Sheltered & AY545647 & $105-590$ & A201G, C207Y & MF285587 \\
\hline
\end{tabular}


Table 4 Mixed infections and discordant typing results detected in canine-derived Giardia duodenalis isolates at the glutamate dehydrogenase (gdh) and/or the beta-giardin (bg) loci, Castellón, Eastern Spain, 2014-2016. GenBank accession numbers are provided

\begin{tabular}{llllll}
\hline Dog status & gdh locus & GenBank accession number & bg locus & GenBank accession number & Assigned genotype \\
\hline Breeding & - & - & All + B & MF285596 & All + B \\
Breeding & BIV + D & MF285588 & Alll+B & MF285597 & Alll+BIV + D \\
Breeding & D & MF285589 & A $^{a}+$ B + D & MF285598 & A + B + D \\
Sheltered & BIII/BIV & MF285590 & B & MF285599 & BIII/BIV \\
Hunting & BIII/BIV & MF285591 & - & - & BIII/BIV \\
Hunting & BIII/BIV & MF285592 & All & MF285600 & All + BIII/BIV \\
Hunting & D & MF285593 & All & MF285601 & All + D \\
Hunting & BIV & MF285594 & All & MF285602 & All + BIV \\
Hunting & BIII/BIV & MF285595 & All & MF285603 & All + BIII/BIV \\
\hline
\end{tabular}

${ }^{a}$ No molecular typing at the sub-assemblage level was possible

Sub-genotyping data of the 10 isolates with only single-assemblage infections at the $b g$ marker are shown in Table 3. Multiple sequence alignment analyses revealed the presence of four distinct genotypes within AII that varied from one to four SNPs when compared over a 490-bp fragment ranging from positions 97/106 to $587 / 590$ of reference sequence AY072723. One of them (MF285580) corresponded to an AII genetic variant not previously reported. A single AIII isolate was identified, differing in three heterozygous positions from a 488-bp stretch between positions 103-590 of reference sequence AY072724. Importantly, the most prevalent B genotype found in Spanish symptomatic patients (KT310386) [33] was also detected in one of the canine isolates investigated at the $b g$ locus in the present study. A novel C genotype (MF285584) revealing two polymorphic sites at positions 37 ( $\mathrm{G}$ to $\mathrm{A}$ ) and 451 ( $\mathrm{C}$ to $\mathrm{T}$ ) of reference sequence AY545646 was also found, whereas the three isolates genotyped as assemblage $\mathrm{D}$ differed from none to four SNPs in a 486-bp stretch (positions 105-590) of reference sequence AY545647.

\section{Discussion}

Few epidemiological surveys have been aimed at investigating the occurrence of G. duodenalis in Spanish dog populations. Microscopy-based surveys have estimated the prevalence of G. duodenalis at $6-38 \%$ in the northeast $[18,19]$, at $1-10 \%$ in the south $[20,22]$, and at $7-$ $16 \%$ in the central areas $[23,24]$ of the country. Based on the same methodology, G. duodenalis cysts have also been found in $5-18 \%$ of faecal droppings and soil samples collected in public parks of the latter region [25]. Overall, these figures were well in the range of those reported usually in other European countries [34, 35]. Comparatively higher prevalences of $29-33 \%$ have been found in northern Spain when qPCR was the detection method of choice [14, 21], much closer to the $36.5 \%$ value identified in the present survey using another high-sensitivity method such as DFAT. Taking together, these data confirm that microscopy examination severely underestimate the actual prevalence of $G$. duodenalis [7]. Of interest, a relatively high proportion $(\sim 20 \%)$ of the canine samples that tested positive by DFAT could not be confirmed by qPCR. This was somehow unexpected, as a previous survey conducted by our lab with stool samples of human origin clearly demonstrated that qPCR had a superior diagnostic sensitivity over DFAT [32]. A potential explanation for this finding is that qPCR failure may be associated, at least partially, to the presence of inhibitory substances in the canine faecal specimens tested.

Our results indicate that G. duodenalis infection primarily presented as a sub-clinical, asymptomatic (as suggested by the absence of diarrhoeal episodes) disease in the surveyed canine communities. Although exact age could not be established, the vast majority of the sampled dogs were young adults or mature animals, suggesting that acquired immunity may play a role in the control and/or severity of the infection [8]. Indeed, no recurrence of Giardia was reported from dogs older than 1 year which attended at a veterinary hospital in USA during an 11-year period [36]. Indirect support for this phenomenon was provided by i) typically low G. duodenalis cyst counts obtained during DFAT examination, and ii) relatively high $\mathrm{Ct}$ values obtained during $\mathrm{qPCR}$. Taken together, these findings indicate that low-to-moderate G. duodenalis burden was the norm in most of the infected dogs detected in the present study. Importantly, shedding of limited cyst numbers would negatively impact the diagnostic sensitivity of the PCR-based methods used for genotyping and sub-genotyping purposes, a fact further aggravated when considering that both $g d h$ and $b g$ markers are single-copy genes. Very similar findings have been previously documented in other canine studies in Spain [14, 21]. 


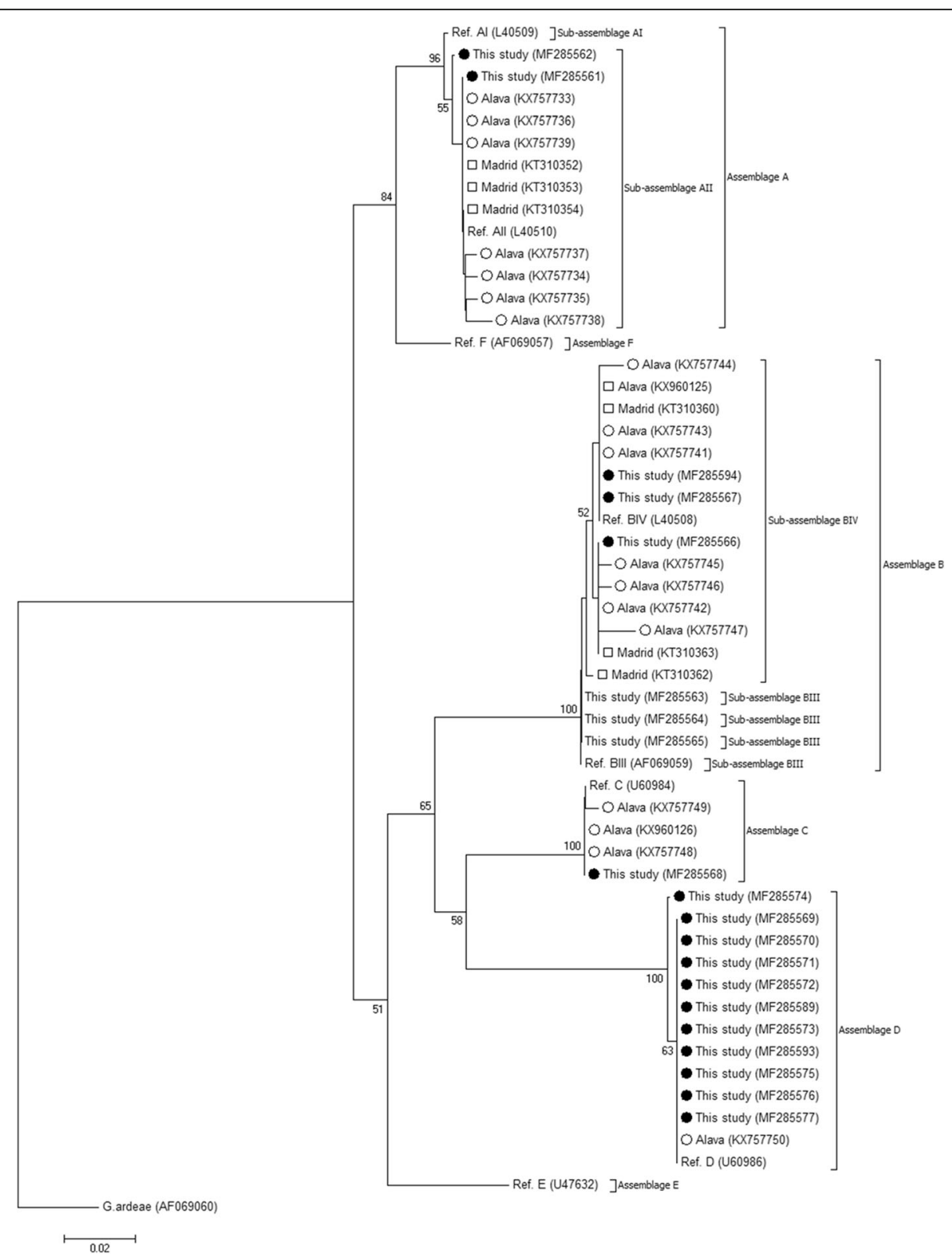

Fig. 2 Phylogenetic tree depicting evolutionary relationships among assemblages of $G$ duodenalis at the gdh locus. The analysis was inferred using the Neighbor-Joining method of the nucleotide sequence covering a 359-bp region (positions 103 to 461 of GenBank accession number L40508) of the gene. Bootstrap values lower than $50 \%$ were not displayed. Filled circles represent canine sequences from this study. Open circles and squares indicate canine and human sequences, respectively, reported in other Spanish studies $[14,21,32]$. Giardia ardeae was used as outgroup taxa

Marked differences in G. duodenalis prevalences were observed among the dog communities investigated here. Sheltered and breeding dogs had a significantly higher prevalence compared to hunting dogs, but not compared to other dog categories. Kennel dogs have been demonstrated to be at higher risk of infection due to continuous exposure to G. duodenalis cysts in kennels with high animal density $[6,8,37]$. Of interest was also the high (35.7\%) prevalence of $G$. duodenalis observed in pet dogs, a potentially serious public health concern if infected animals are in close contact with children or immunocompromised individuals. Because none of the G. duodenalis isolates obtained from pet dogs in the present survey could be genotyped at the assemblage level, more research should be conducted to elucidate the actual role of domestic dogs as natural reservoirs of human giardiosis. Finally, hunting dogs exhibited the lowest (20.6\%) G. duodenalis infection rate, a figure in the lower range of those (20-30\%) reported in similar studies conducted in Spain [19] and Italy [37]. 
As anticipated, our genotyping analyses confirmed that canine-specific assemblages $C$ and $\mathrm{D}$, particularly the latter, were the most prevalent genetic variants of G. duodenalis circulating in dogs in the province of Castellón. Assemblages C/D are known to account for $~ 70 \%$ of the cases of canine giardiosis documented in European countries [10, 38, 39], including Croatia [40], Germany [41], Greece [42], and Spain [14, 19]. However, this genotype frequency pattern may vary according to the geographical region and/or the dog population considered. For instance, potentially zoonotic assemblages A/B have been found in $69-89 \%$ of the canine isolates genotyped in a number of Spanish [21, 24], German [43], and North American [44] molecular investigations. Remarkably, one in five of our canine infections involved different combinations of $G$. duodenalis assemblages. The fact that the vast majority of these mixed intra-assemblage infections were found in kennelled animals was well in agreement with the former observation that these dogs underwent high infection pressures associated with crowded living conditions (see above). In this regard, mixed intra-assemblage infections have been documented in $2-27 \%$ of the canine isolates genotyped in Europe [10] and up to $39 \%$ of those from developing countries [13]. In Spain, no mixed G. duodenalis infections were demonstrated in two independent molecular surveys based on PCR and sequencing analyses targeting sheltered and pet dogs in the north of the country [14, 21 , although an unprecedented mixed infection rate of $48 \%$ was allegedly reported in an earlier study based on PCR-RFLP [24].

Sub-genotyping analyses at both the $g d h$ and $b g$ loci also revealed exciting molecular data. For instance, AII sequences confirmed the high genetic diversity previously reported in canine isolates of this particular subassemblage in other Spanish regions [21], with virtually all analysed sequences exhibiting a different pattern of SNP frequency including well-defined point-mutations and heterozygous (double peaks) sites. Interestingly, this phenomenon does not seem to occur in Spanish human isolates, where most (75-100\%) of the AII sequences sub-genotyped to date at those very same markers were identical among them [32, 45]. The finding that AII isolates of canine origin present considerably higher levels of heterogeneous nucleotides at both $g d h$ and $b g$ genes than those of human origin has two important consequences. Firstly, it may supports the existence of genetic exchange, challenging the still widely accepted (but gradually changing) notion that Giardia is an organism strictly asexual [46]. In this regard, allelic sequence heterozygosity [47], intragenic recombination [48], and nuclear fusion within cysts [49] have been proposed as potential driving mechanisms of recombination processes in Giardia. Additionally, recombination events would be enhanced in epidemiological scenarios characterized by high prevalence rates and elevated infection pressures as those locally described in the present study. Indeed, intra-assemblage recombination has been already demonstrated in AII and B isolates in a highly endemic area in Peru $[13,50]$. Secondly, it provides direct molecular evidence disfavouring the role of dogs as natural reservoirs of human giardiosis. Worthy of note was also the identification in a single canine isolate of AIII, a sub-assemblage essentially found in cattle and wild ruminants $[10,11]$.

Less surprising was the demonstration of high levels of genetic diversity within the canine isolates assigned to sub-assemblages BIII and BIV, in line with previously reported genotyping data in both canine $[14,21]$ and human $[33,45]$ populations in Spain and other countries $[10,11]$. Notably, two independent canine B isolates were confirmed identical at the $g d h$ (MF285566) or the $b g$ (MF285583) genes to those predominantly found circulating in Spanish symptomatic patients [33, 45]. This is the only molecular evidence found in the present study backing up dogs as a potential source of human infections in Castellón, although we cannot rule out the possibility of anthroponotic transmission. More moderate, but still relevant, levels of genetic diversity at the nucleotide level were observed within caninespecific assemblages $C / D$, as clearly demonstrated by the identification of 12 known and one novel assemblage D genotypes.

\section{Conclusions}

Prevalence data presented here are consistent with an epidemiological scenario in which G. duodenalis is common in dogs, typically presenting as a light, asymptomatic infection. Highly endemic foci of disease were detected in breeding kennels and dog shelters where infection pressures were high. Although a significant proportion of the infected dogs harboured potentially zoonotic assemblages and sub-assemblages of G. duodenalis, most of these genotypes seemed to be primarily transmitted within canine cycles and posed, therefore, a limited risk to humans. However, the actual extent of this statement must be corroborated in future molecular epidemiological surveys including human and dog puppy isolates from this Spanish geographical area.

\section{Additional files}

Additional file 1: Table S1. Oligonucleotides used for the molecular identification and characterization of Giardia duodenalis in this study. (DOCX $13 \mathrm{~kb})$

Additional file 2: Figure S2. Histogram of cycle threshold $(\mathrm{Ct})$ values obtained by real-time PCR for the detection of Giardia duodenalis in DNA isolates from canine faecal samples. (DOCX $31 \mathrm{~kb}$ ) 


\section{Abbreviations}

bg: B-giardin; bp: base pair; Cl: Confidence interval; Ct: Cycle threshold; DFAT: Direct fluorescent antibody test; DNA: Deoxyribonucleic acid; dNTP: Deoxynucleotide triphosphate; gdh: Glutamate dehydrogenase; NCBI: National Center for Biotechnology Information; PCR: Polymerase chain reaction; qPCR: Real-time polymerase chain reaction; RFLP: Restriction fragment length polymorphism; RNA: Ribonucleic acid; SD: Standard deviation; SNP: Single-nucleotide polymorphism; SSU rRNA: Small subunit ribosomal RNA; UK: United Kingdom; USA: United Satates of America

\section{Acknowledgments}

The authors are grateful to Sandra Diago Porcar for her technical assistance during sampling and methodological procedures.

\section{Funding}

This study was funded by the Health Institute Carlos III, Ministry of Economy and Competitiveness under project CP12/03081. Additional funding was obtained from the CEU-Santander/Zoocan Study.

\section{Availability of data and materials}

All relevant data are within the paper and its Supporting Information files. Generated sequence data are accessible from public repository databases (GenBank)

\section{Authors' contributions}

PST, MADA, and DC designed the study protocol, supervised laboratory analyses, analysed and interpreted the data. DC wrote the first draft of the manuscript. MAA, ADL, PP, and MHDM contributed to the laboratory analyses. PCK conducted sequence and phylogenetic analyses and revised molecular data. All authors read and approved the final version of the manuscript

\section{Ethics approval}

This study was carried out in compliance with the national animal welfare regulations. Diagnostic veterinary procedures are not within the context of relevant EU legislation for animal experimentation (Directive 86/609/EC) and may be performed in order to diagnose animal diseases and improve animal welfare. Faecal droppings were collected by trained personnel who ensured owners consent and caused neither harm nor suffering to the investigated animals.

\section{Consent for publication}

Not applicable.

\section{Competing interests}

The authors declare that they have no competing interests.

\section{Publisher's Note}

Springer Nature remains neutral with regard to jurisdictional claims in published maps and institutional affiliations.

\section{Author details}

${ }^{1}$ CEU Cardenal Herrera University, C/ Grecia, 31, 12006 Castellón de la Plana, Castellón, Spain. ${ }^{2}$ Parasitology Reference and Research Laboratory, National Centre for Microbiology, Health Institute Carlos III, Ctra. Majadahonda-Pozuelo Km 2, 28220 Majadahonda, Madrid, Spain. ${ }^{3}$ CEU Cardenal Herrera University, C/ Luis Vives 1, 46115 Alfara del Patriarca, Valencia, Spain.

Received: 11 August 2017 Accepted: 16 January 2018

Published online: 22 January 2018

\section{References}

1. Pet Food Manufacturers Association, 2016 Pet population 2016. http:// wwwpfmaorguk/pet-population-2016. Accessed 15 July 2017.

2. Hodgson K, Barton L, Darling M, Antao V, Kim FA, Monavvari A. Pets' impact on your patients' health: leveraging benefits and mitigating risk. J Am Board Fam Med. 2015:28:526-34.

3. Snipelisky D, Burton MC. Canine-assisted therapy in the inpatient setting South Med J. 2014;107:265-73.

4. Esch KJ, Petersen CA. Transmission and epidemiology of zoonotic protozoan diseases of companion animals. Clin Microbiol Rev. 2013;26: 58-85.
5. Baneth G, Thamsborg SM, Otranto D, Guillot J, Blaga R, Deplazes P, et al. Major parasitic zoonoses associated with dogs and cats in Europe. J Comp Pathol. 2016;155:S54-74.

6. Ballweber LR, Xiao L, Bowman DD, Kahn G, Cama VA. Giardiasis in dogs and cats: update on epidemiology and public health significance. Trends Parasitol. 2010;26:180-9.

7. Bouzid M, Halai K, Jeffreys D, Hunter PR. The prevalence of Giardia infection in dogs and cats, a systematic review and meta-analysis of prevalence studies from stool samples. Vet Parasitol. 2015;207:181-202.

8. Tysnes KR, Skancke E, Robertson L. Subclinical Giardia in dogs: a veterinary conundrum relevant to human infection. Trends Parasitol. 2014;30:520-7.

9. Westermarck E. Chronic diarrhea in dogs: what do we actually know about it? Top Companion Anim Med. 2016:31:78-84.

10. Feng Y, Xiao L. Zoonotic potential and molecular epidemiology of Giardia species and giardiasis. Clin Microbiol Rev. 2011;24:110-40.

11. Ryan U, Cacciò SM. Zoonotic potential of Giardia. Int J Parasitol. 2013;43: 943-56.

12. Inpankaew T, Schär F, Odermatt $P$, Dalsgaard A, Chimnoi W, Khieu V, et al. Low risk for transmission of zoonotic Giardia duodenalis from dogs to humans in rural Cambodia. Parasit Vectors. 2014;7:412.

13. Cooper MA, Sterling CR, Gilman RH, Cama V, Ortega Y, Adam RD. Molecular analysis of household transmission of Giardia lamblia in a region of high endemicity in Peru. J Infect Dis. 2010;202:1713-21.

14. de Lucio A, Bailo B, Aguilera M, Cardona GA, Fernández-Crespo JC, Carmena D. No molecular epidemiological evidence supporting household transmission of zoonotic Giardia duodenalis and Cryptosporidium spp. from pet dogs and cats in the province of Álava, northern Spain. Acta Trop. 2017; 170:48-56.

15. Inpankaew T, Traub R, Thompson RC, Sukthana Y. Canine parasitic zoonoses in Bangkok temples. Southeast Asian J Trop Med Public Health. 2007;38: 247-55

16. Volotão AC, Costa-Macedo LM, Haddad FS, Brandão A, Peralta JM, Fernandes $\mathrm{O}$. Genotyping of Giardia duodenalis from human and animal samples from Brazil using beta-giardin gene: a phylogenetic analysis. Acta Trop. 2007;102:10-9.

17. Carmena D, Cardona GA, Sánchez-Serrano LP. Current situation of Giardia infection in Spain: implications for public health. World J Clin Infect Dis. 2012;2:1-12.

18. Gracenea M, Gómez MS, Torres J. Prevalence of intestinal parasites in shelter dogs and cats in the metropolitan area of Barcelona (Spain). Acta Parasitol. 2009;54:73-7.

19. Ortuño A, Scorza V, Castellà J, Lappin M. Prevalence of intestinal parasites in shelter and hunting dogs in Catalonia. Northeastern Spain Vet J. 2014;199: 465-7.

20. Martínez-Moreno FJ, Hernández S, López-Cobos E, Becerra C, Acosta I, Martínez-Moreno A. Estimation of canine intestinal parasites in Córdoba (Spain) and their risk to public health. Vet Parasitol. 2007;143:7-13.

21. Gil H, Cano L, de Lucio A, Bailo B, de Mingo MH, Cardona, et al. Detection and molecular diversity of Giardia duodenalis and Cryptosporidium spp. in sheltered dogs and cats in northern Spain. Infect Genet Evol. 2017;50:62-9.

22. Martínez-Carrasco C, Berriatua E, Garijo M, Martínez J, Alonso FD, de Ybáñez RR. Epidemiological study of non-systemic parasitism in dogs in southeast Mediterranean Spain assessed by coprological and post-mortem examination. Zoonoses Public Health. 2007:54:195-203.

23. Miró G, Mateo M, Montoya A, Vela E, Calonge R. Survey of intestinal parasites in stray dogs in the Madrid area and comparison of the efficacy of three anthelmintics in naturally infected dogs. Parasitol Res. 2007;100:317-20.

24. Dado D, Montoya A, Blanco MA, Miró G, Saugar JM, Bailo B, et al. Prevalence and genotypes of Giardia duodenalis from dogs in Spain: possible zoonotic transmission and public health importance. Parasitol Res. 2012;111:2419-22.

25. Dado D, Izquierdo F, Vera O, Montoya A, Mateo M, Fenoy S, et al. Detection of zoonotic intestinal parasites in public parks of Spain potential epidemiological role of microsporidia. Zoonoses Public Health. 2012;59:23-8,

26. Cardona GA, Carabin H, Goñi P, Arriola L, Robinson G, Fernández-Crespo JC, et al. Identification and molecular characterization of Cryptosporidium and Giardia in children and cattle populations from the province of Álava, north of Spain. Sci Total Environ. 2011;412-3:101-8. doi:https://doi.org/10.1016/j. scitotenv.2011.09.076.

27. Instituto Nacional de Estadística. http://www.ine.es/. Accessed 4 Dec 2017.

28. Rivia (Registro Informático Valenciano de Identificación Animal). http:// wwwriviaorg/. Accessed 4 Dec 2017. 
29. Verweij JJ, Schinkel J, Laeijendecker D, van Rooyen MA, van Lieshout L, Polderman AM. Real-time PCR for the detection of Giardia lamblia. Mol Cell Probes. 2003;17:223-5.

30. Read CM, Monis PT, Thompson RC. Discrimination of all genotypes of Giardia duodenalis at the glutamate dehydrogenase locus using PCR-RFLP. Infect Genet Evol. 2004:4:125-30.

31. Lalle M, Pozio E, Capelli G, Bruschi F, Crotti D, Cacciò SM. Genetic heterogeneity at the beta-giardin locus among human and animal isolates of Giardia duodenalis and identification of potentially zoonotic subgenotypes. Int J Parasitol. 2005;35: 207-13.

32. Tamura K, Stecher G, Peterson D, Filipski A, Kumar S. MEGA6: molecular evolutionary genetics analysis version 6.0. Mol Biol Evol. 2013;30:2725-9.

33. de Lucio A, Martínez-Ruiz R, Merino FJ, Bailo B, Aguilera M, Fuentes I, et al. Molecular genotyping of Giardia duodenalis isolates from symptomatic individuals attending two major public hospitals in Madrid, Spain. PLoS One. 2015;10:e0143981.

34. Overgaauw PA, van Zutphen L, Hoek D, Yaya FO, Roelfsema J, Pinelli E, et al. Zoonotic parasites in fecal samples and fur from dogs and cats in The Netherlands. Vet Parasitol. 2009;163:115-22.

35. Epe C, Rehkter G, Schnieder T, Lorentzen L, Kreienbrock L. Giardia in symptomatic dogs and cats in Europe-results of a European study. Vet Parasitol. 2010;173:32-8.

36. Gates MC, Nolan TJ. Endoparasite prevalence and recurrence across different age groups of dogs and cats. Vet Parasitol. 2009;166:153-8.

37. Pipia AP, Varcasia A, Tamponi C, Sanna G, Soda M, Paoletti B, et al. Canine giardiosis in Sardinia Island, Italy: prevalence, molecular characterization, and risk factors. J Infect Dev Ctries. 2014;8:655-60.

38. Sprong H, Cacciò SM, van der Giessen JW. Identification of zoonotic genotypes of Giardia duodenalis. PLoS Negl Trop Dis. 2009;3:e558.

39. Sommer MF, Beck R, lonita M, Stefanovska J, Vasić A, Zdravković N, et al. Multilocus sequence typing of canine Giardia duodenalis from south eastern European countries. Parasitol Res. 2015;114:2165-74.

40. Beck R, Sprong H, Pozio E, Cacciò SM. Genotyping Giardia duodenalis isolates from dogs: lessons from a multilocus sequence typing study. Vector Borne Zoonotic Dis. 2012;12:206-13.

41. Pallant $L$, Barutzki D, Schaper R, Thompson RC. The epidemiology of infections with Giardia species and genotypes in well cared for dogs and cats in Germany. Parasit Vectors. 2015;8:2.

42. Kostopoulou D, Claerebout E, Arvanitis D, Ligda P, Voutzourakis N, Casaert S, et al. Abundance, zoonotic potential and risk factors of intestinal parasitism amongst dog and cat populations: the scenario of Crete, Greece. Parasit Vectors. 2017:10:43.

43. Leonhard S, Pfister K, Beelitz P, Wielinga C, Thompson RC. The molecular characterisation of Giardia from dogs in southern Germany. Vet Parasitol. 2007;150:33-8

44. Covacin C, Aucoin DP, Elliot A, Thompson RC. Genotypic characterisation of Giardia from domestic dogs in the USA. Vet Parasitol. 2011;177:28-32.

45. Azcona-Gutiérrez JM, de Lucio A, Hernández-de-Mingo M, García-García C, Soria-Blanco LM, Morales L, et al. Molecular diversity and frequency of the diarrheagenic enteric protozoan Giardia duodenalis and Cryptosporidium spp. in a hospital setting in northern Spain. PLoS One. 2017;12:e0178575.

46. Adam RD. Biology of Giardia lamblia. Clin Microbiol Rev. 2001;14:447-75.

47. Ankarklev J, Svärd SG, Lebbad M. Allelic sequence heterozygosity in single Giardia parasites. BMC Microbiol. 2012;12:65

48. Kosuwin R, Putaporntip C, Pattanawong U, Jongwutiwes S. Clonal diversity in Giardia duodenalis isolates from Thailand: evidences for intragenic recombination and purifying selection at the beta giardin locus. Gene. 2010;449:1-8.

49. Poxleitner MK, Carpenter ML, Mancuso JJ, Wang CJ, Dawson SC, Cande WZ. Evidence for karyogamy and exchange of genetic material in the binucleate intestinal parasite Giardia intestinalis. Science. 2008;319:1530-3.

50. Cooper MA, Adam RD, Worobey M, Sterling CR. Population genetics provides evidence for recombination in Giardia. Curr Biol. 2007;17:1984-8.

\section{Submit your next manuscript to BioMed Central and we will help you at every step:}

- We accept pre-submission inquiries

- Our selector tool helps you to find the most relevant journal

- We provide round the clock customer support

- Convenient online submission

- Thorough peer review

- Inclusion in PubMed and all major indexing services

- Maximum visibility for your research

Submit your manuscript at www.biomedcentral.com/submit
Biomed Central 